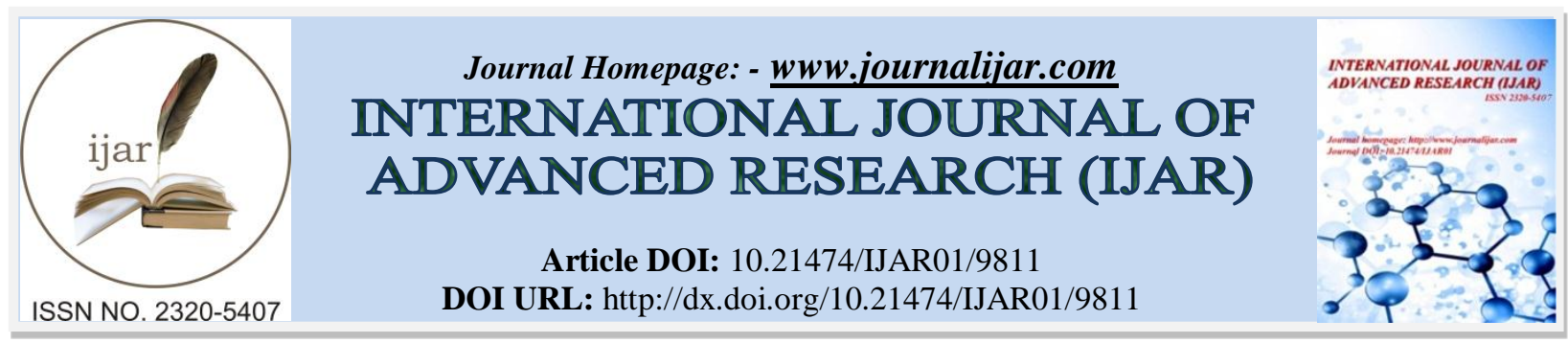

RESEARCH ARTICLE

\title{
INTERORGANIZATIONAL COORDINATION TOWARDS DOMESTIC VIOLENCE PREVENTION: A CASE FROM GHANA.
}

Edward Fosu and Deborah Asiedu.

\section{Manuscript Info}

\section{Manuscript History}

Received: 04 August 2019

Final Accepted: 06 September 2019

Published: October 2019

Keywords:-

Inter-organizational Coordination, Feminist and Socio-structural Theories, Interpersonal Theory and Social and Learning Theories

\begin{abstract}
Mostly, domestic violence is perceived as private affairs in some societies, people pay minimum heed to the damages and effects it has on the psychological, mental, emotional and bodily development of these victims. Coupled with these occurrences is the organization's incompetence to address victims' cases and prevent citizens from violation of their rights. This research paper aimed to handle the situation from an organizational perspective. Conditions that call for inter-organizational coordination are mostly the ones in which no upper authority to direct how the cooperating organizations will work together.

The study at large provides a justification for future study of how formal information sharing, task specification and common organizational culture for coordination may help coordinators foster the motive of the set goals to be attained and ultimately achieve effective inter-organizational coordination. To study these occurrences, a quantitative method was adopted and questionnaires were employed or used to elicit data that were gathered to understand clearly the situation that arise the coordination complications between the agencies and if there's an existence of coordination among them at all. The research depicted that, no inter-organizational coordination in handing cases among the organizations was there, instead; they address reported cases independently within their capacity by not involving the other organizations. Ideas were beseeched about inter-organizational coordination, apparently, workers have a fair knowledge and its' importance. Most workers from CHRAJ and DOVVSU testified to it that; communication and organizational structures have been the impediments for better performances as the populace sees organizations as ineffective in case management.
\end{abstract}

Copy Right, IJAR, 2019,. All rights reserved.

\section{Introduction:-}

Domestic violence towards children and women have been seen by this generation as a known secret. Most women and children worldwide experience violation of their human rights one way of the other. Domestic violence around the continents is seen or accepted as an offensive act or criminal. Yet these unwanted and abusive behaviors against mankind keeping on recurring in communities, societies and the country at large unpunished, because of numerous factors that institutions and governments aiming or making great efforts to address. Predominantly domestic violence remains both sexual and physical abuse with the neglecting of the further abusive actors like economical, 
emotional, and psychological. The UN describes partner violence similarly as: sexual violence (rape or other of nonconsensual sexual activity), physical violence (any physical contact), stalking (harassing tactics that cause fear), psychological aggression (insulting, humiliating, or verbal coercion), or sexual health (non- consensually birth control). Thus any coercion, liberty deprivation, physical actions and sexual act that harm the lives of women are categorized as gender-based violence. The international society has placed maximum emphasis on "gender-based violence". Michele C. Black, et. al (2010) These lay greater emphasis that women's rights are mostly trampled upon in the societies, notwithstanding the effects on the children at large. Mostly, children are susceptible to certain sorts of violence somehow. Children are fragile and ignorance of human rights. UN Committee on child's rights recognizes numerous types of violence related to children, including negligent treatment, mental violence, physical violence, sexual abuse, corporal punishment, inhuman violence, exploitation, torture and institutional or system violence. CRC General Comment No. 13, (2003). The child's rights are susceptible to distinctive protection and attention and are different from that of women, given that guardians and parents have the responsibilities in the upbringing of their wards, shield them from any kind of violence, maltreatment and the state has obligations to accomplish in these regards. T. A Secretariat (2015). These assertions stipulate they are highly vulnerable and are much endangered to violence than men; hence they must be protected by states' institutions. The International Communities worldwide have made vigorous efforts putting measures, regulations and laws to defend these lawful rights of women along with children; similarly, countries like Ghana are not exempted from domestic violence. Ghana with a 30 million estimated population, where women, the youth, and children constitute the greater portion face challenges of rights abuses, injustice and domestic violence. Ghana is a multi-national country with more than 75 ethnic groups, its' citizens are highly traditional and have a solid attachment to some cultural practices, these practices mostly conflict with human rights laws; making it a problematic for constitutional organizations to deal with. Ghana like any developing country is faced with Gender disparities, rights violations and child labor. As part to realize the Objectives of (MDG), including the eradication of poverty, hunger, gender equality, empowering women and education. Social protection policies and law's enactment and programs become effective mechanisms in helping vulnerable and populations at lager through state efforts.

Ghana has made many efforts to control human rights infringement and injustices, under the 1992 constitution of Ghana; CHRAJ was established to enhance social progress by means of defending and enforcing essential fundamental human rights and freedoms for all persons in Ghana. Ghana Report on Domestic Violence Act 2007, (2018) The commission has the national human rights institution as a fraction of its agencies to prevent, safeguard the legal rights of peoples living with disabilities, children and women and inform citizens or populace on their basic citizens' rights. The effort by civil organizations mounting pressure on the government to include domestic violence on governments' agenda and resultantly ensure its bland passage into law was accompanied by challenges; accordingly, Ghana enacted the Domestic Violence Act, in February 2007. Dery, (2014) Developed countries have laws and specific police Units as a strategy for implementing gender-based violence policies. Hera, I.V (2014) DOVVSU became established in 1998, formally known to be WAJU. Its purpose is to prevent, protect, apprehend and prosecute perpetrators of domestic violence and child abuse". The Unit is tasked to deliver services freely, public education and refer victims to the appropriate institution for medical treatments and counseling.

However, the paucity of resources for CHRAJ and DOVVSU in addressing all cases hinders the ability to handle the situation. Also, funding remains a challenge for administers of the state's institutions in fighting against domestic violence. Strategies for gender-based violence response and prevention designate the necessity for multi-sectoral coordination and inter-organizational involvement. Bott, Morrison and Ellsberg, (2005) An established plan must be coordinated by interagency actors to safeguarding the implementation; that makes it necessary for DOVVSU and CHRAJ to coordinate and collaborate to enforce the Act.

\section{Research Objectives:-}

Organizations are coupled with challenges that made them incapacitated to deliver to expectation in addressing domestic violence cases. In view of this, the ultimate objective of the research paper is to study existing coordination and suggest mechanisms that will coordinate the activities of DOVVSU and CHRAJ to effective handling of domestic violence and child abuse cases.

This research work seeks to address how through inter-organizational coordination, policy actors will effectively implement this law with the available resources viewing Ghana as a developing and multinational country. 


\section{Research questions;}

1. How do DOVVSU and CHRAJ address domestic violence cases?

2. What are the effective mechanisms to promote inter-organizational coordination between DOVVSU and CHRAJ?

\section{Problem Statement}

Violence prevention activities are mostly handled by many agencies without the main agency in coordination. In a multi-sectoral approach, leadership and mechanisms to manage the activities of different sectors to effect fruitful outcome between the institutions is a key factor. Most countries having multiple departments taking responsibility for violence prevention and response efforts with an average of five departments listed per country. By sector agencies responsible for gender and women's affairs were commonly social welfare, interior, health, and police. However, the presence of the lead department to coordinate the actions of these sectors and report periodically on improvement in preventing violence was rare. Lack of clear leadership to supervise all the preventive activities throughout the country makes it challenging for agencies to strategically invest resources, avoid duplication and ensure accountability. The majority of countries reported placing systems for regular exchange or sharing of information between agencies and sectors in violence prevention. The egalitarianism of mankind has been the ultimate foundation for development recently in our world. Domestic violence by women against men or vice versa is rampant in loads of cultures also the rate of proliferation is alarming. These happenings are been well-thought-out by the UN and other international bodies of which Ghana is an affiliate as a breach/infringement of human rights. Contrary to efforts made by the UN, research done in Ghana bring into being that domestic violence cases in all its kinds are rampant in Ghana and that sufferers of abuse sustained injuries after beatings. Institute of Development Studies (IDS),(2016)

Besides the efforts made by Ghana governments to protect and secure the civil rights of all vulnerable citizens, domestic violence exists and assumed as a social canker difficult to manage. Government institutions have singlehanded implemented policies for resolving the problem. Nevertheless, these stipulated measures have not fully accomplished their tasks. Insufficient funding, infrastructure, resourced personnel and inadequate resources have bestowed to the flaws of the prevention policies Kissi (2012). Some personnel or workers seem to have inadequate knowledge and expertise necessary for tackling the complete issues head-on putting into perspective the cultural setting within which such cases occur given that it appears the Unit lacks adequate programs for training personnel distinct from the traditional policing programmers needed for delivering quality services. Kissi, (2012) Logistics insufficiency and inadequate financial wealth had to render CHRAJ redundant, published by the Ghanaweb, (2010). These causes depict that both organizations face numerous administrative challenges; nevertheless, the states' institutions need to manage and operate with the limited available resources, adapt to coordinating strategies to curb the situation from deteriorating.

\section{Theories of Domestic violence Feminist and Socio-structural Theories}

Feminist theories have been predominantly influential in unveiling the domestic violence issue, campaigning for change, and in sponsoring pragmatic actions to solve abuse. They draw on the accounts of comprehending how patriarchal attitudes, institutions and gendered power differentials have fostered inequality, male privilege, and a sense of male entitlement. Violent behavior operates as a route to achieving and maintaining male domination, power and control. Barnish (2004) The Sustenance for the feminist perspective comes from cross-cultural ethnographic studies demonstrating violence towards women is more endemic in cultures and sub-cultures where men dominate decision-making and allocate fixed, deferential gender roles to women. Krug, Mercy, Dahlberg et, (2002) Socio-political theories point out structural discrimination as the source of men's violence towards women.

Although domestic violence befalls across all social strata, there is an indication and evidence that men with lower socio-economic status commit more domestic violence. Socio-structural theories also enlighten abuse as a stress reaction to a masculine identity crisis in situations of relative deprivation, unemployment, or changing gender roles. Heise, (1998) The theories have been censured for ignoring individual differences, failing to clarify why most men (and most poor men) are not cruel to women, or why violence takes place in lesbian relationships. Dutton, Bennett, Goodman et. al (2001) The theories suggestions to address domestic violence include macro-level transforms to social norms and structures, focused on policy and law which take public ownership of the issue and implements a systematic, proactive technique to eliminating domestic violence. From their perspective, interventions must mostly focus on improving women's security and safety, whilst also safeguarding men's accountability via formal criminal justice and informal controls measures. Public expenditure should not rank higher culprit rehabilitation over victim 
services and safety. Resources ought to be used-up on efforts to change perpetrators to re-socialize and re-educate men to accept guilt for their violence. Hamberger, L.K. \& Hastings (1998) Interventions with culprits based on feminist models have been located within an organized community response with dual goals of victim well-being and offender answerability. Education, challenge and re-socialization techniques are used to increase men's understanding and enactment of mutual equality and respect, and their acceptance of guilt-ridden for their act. Barner, J.R. \& Carney, (2011) Programs for abusers centered on a solely feminist model have raised alarms that information-giving alone may not enable change and that a confrontational approach may alienate some participants, further entrench behavior, and compel change by use of power and control. Hamberger, L.K. \& Hastings (1998)

\section{Interpersonal Theories}

Interpersonal perspectives on the reasons for domestic violence are located within relationship conflict. Poor communication and ineffective conflict resolution characterized in the family or between spouses are thought to produce dysfunctional violence-prone family systems that perpetuate problematic behaviors. Therefore every family member or partner is considered a contributor to the causes of violence Hamberger, L.K. \& Hastings (1998). Family systems theories and its' interventions are criticized for discounting the power dynamics in relationships, blaming victims and/or requiring them to transform or change behavior that as not to incite an attack, increasing the risk of further abuse, and for failing to hold perpetrators responsible. Humphreys et al. (2001)Interventions suggested by family systems viewpoints are gender-neutral relationship or family counseling concerning both partners, focused on improving and refining interpersonal, communication and negotiating skills. Cunningham et al. (1998)

\section{Social and Learning Theories}

The perspectives from Social theories concentrate on the influences of the understanding of an individual's social context like attitudes, social norms, and values to violence. Learning theories regard violence and its' attitudes that follow or accompany it, as learned through imitation. Hamberger, L.K. \& Hastings (1998) The individual learns the functional value or importance of violence for achieving or obtaining desired outcomes by witnessing the repercussions of behavior modeled by others with whom they identify, or via discerning the values of their own behavior. Behavior is rewarded and reinforced by its effects. Edleson, (1998) Evidence of intergenerational violence transmission comes from longitudinal and ethnographic research that observes the relationships between childhood influences and later adult behavior. Jewkes, Dunkle, Nduna et. al, (2010) Witnessing domestic violence as a child appears as one of the powerful prognosticators of later violence perpetration. Hotaling, G.T. \& Sugarman, (1990) However, the theory of social learning cannot explain why most children exposed to adverse violence influences do not intend to perpetrate violence and why a substantial fraction of perpetrators report no exposure to family violence. Hague, Mullender, Thiara et. al, (2011) Suggested interventions by social learning and social cognition include action to stop children's exposure to violence. For perpetrators, group learning using cognitive-behavioral models or methods, which identifies faulty thinking leading to negative emotion, and exchanges abusive thinking and behavior patterns with new modeled skills and behaviors such as 'self-talk' analysis. Hague et al. (2011) Abuser interventions grounded solely on social learning theories have criticized that they are a 'quick fix' then do not adequately hold the abuser answerable for their adverse behavior, avoid directly addressing the violence, and ignoring the restrain and power dimensions of abuse. Hague et al. (2011)

\section{Inter-organizational Coordination Theory}

The studying of a theoretical approach towards coordination cannot be distinguished from that of other spheres of research in public management Geert Bouckaert and B. Guy Peters, (2010) Theories in public management are essential tools for understanding what pushes and hampers public sector coordination. Institutions in Ghana responsible for managing domestic violence against all persons are being challenged with institutional coordination. As a developing country, personnel, resources, and funding are additional problems facing public policy implementation. Inter-institutional or Inter-organizational coordinating help facilitate implement policies to solve a public problem at a lower cost and with limited resources. In this review, inter-organizational coordination is defined as, the practice by which organizations create, adjust and utilize existing rules established to manage a collective task posited by Geerlings (2002). The emphasis is on existing rules; DOVVSU and CHRAJ are separate state institutions with different organizational structures but somewhat share existing rules. Coordinating the two institutions in curbing domestic violence is discerned as a mutual adjustment strategy. Inter-organizational coordination creates a systematic relationship concerning the decisions of the institutions. Deliberate coordinated decisions or interactions produce desirable outcomes for participants. Lack of coordination is recognized as the major problem that the system of social welfare has to address, viewing coordination by way of the joining together of resources and process to realize the preferred outcome. Jennings, 1994, pointed out the essence of public 
institutions or organizations to coordinate to dispense a remedy to a situated problem. Jennings Edward T and Ewalt, (1998)

By this definition, the challenges faced by both DOVVSU and CHRAJ in the execution of Ghana's (DV) Act against vulnerable women and children can be addressed by this theory. For instance, limited personnel, funding and inadequate infrastructural resources of institutions can be coordinated to manage the violence problem of the country. It has been shown that not all the district headquarters have offices for CHRAJ and DOVVSU operating and directing the operations of the units/organizations so that their joint behavior attains a specific goal with higher probability with a unify expectation of results. The target of coordination mechanisms is to offer a gamut of possible formats for the structural aspect of implementing policies, programs and plans: institutional design by Alexander, (1993). Regarding the implementation to transform the behavioral attitudes towards women and children, the institutional structures of DOVVSU and CHRAJ should be coordinately designed to effectively coordinate the institutions in executing their plans.

\section{Research Methodology:-}

The research used quantitative methodology designs to evaluate the repercussion of inter-organization coordination on organizations' performance towards the prevention of domestic violence. The design espoused close-ended questions aimed at acquiring-depth data of organizational behavior and structure to the case or the problem. A quantitative design was used to gather primary data that focus on obtaining results that were quantified expressed in numbers or percentages. A five (5) Likert scale ranging from strongly disagreed to strongly agreed, strongly disagreed is signified by 1 , disagreed is signified by 2 , neutral is signified by 3 , agreed is signified by 4 and strongly agreed is signified by 5 . The research used the descriptive method. In all, 13 questions were answered by the workers. The first 4 questions were to describe the existing inter-organizational coordination. The remaining 9 questions were employed to solicit the workers' assimilation of the mechanisms of inter-organizational coordination. The tenacity of the descriptive method is to describe a condition or situation not relationships concerning variables. The descriptive method intends to present situational facts; it helps obtain explanatory questions of a phenomenon. Yin (1993) Again, impressions, relationships and discernments of information obtained were inferentially analyzed. The questionnaires were submitted to 150 respondents purposely selected from DOVVSU and CHRAJ workers in the Greater Accra and Ashanti Regions of Ghana. SPSS, well-known computer software was used in analyzing quantitative data.

\section{Results:-}

\section{Descriptive statistics}

The 150 questionnaires received collectively constituted $115(76.7 \%)$ workers from DOVVSU, out of 115,12 $(8.0 \%)$ were males and103 (68.7\%) were females, $35(23.3 \%)$ were workers from CHRAJ and out of 35, $4(2.7 \%)$ and $31(20.7 \%)$ were females and males respectively. In regards to educational qualification; 18(12\%) were WASSCE graduates, 50 (33.3\%) were diploma graduates, 54 (36\%) have undergraduate/bachelor degrees and (28) representing $(18.7 \%)$ have masters/higher degree.

\section{Objective 1}

Table 1:-Represents the responses that were given about the general information on the existing coordination between DOVVSU and CHRAJ.

\begin{tabular}{|l|l|l|l|l|l|}
\hline & $\mathrm{N}$ & Mean & Std. Deviation & Skewness \\
\hline & Statistic & Statistic & Statistic & Statistic & Std. Error \\
\hline (TCDC) & 150 & 2.91 & 1.117 & -.120 & .198 \\
\hline (JSP) & 150 & 3.74 & 1.217 & -.845 & .198 \\
\hline (SIDV) & 150 & 3.63 & 1.138 & -.654 & .198 \\
\hline (DVS) & 150 & 3.38 & 1.369 & -.508 & .198 \\
\hline
\end{tabular}

There was pellucid evidence, that there was the absence of coordination amongst them from respondents given the mean $(\mathrm{M}=2.91, \mathrm{SD}=1.12)$ (TCDC). With respect to information sharing (SIDV), the mean was $(\mathrm{M}=3.63, \mathrm{SD}$ $=1.12$ ) which attests to the point that they lack proper information sharing among the organizations. With the mean of $(\mathrm{M}=3.74, \mathrm{SD}=1.22)$ showing that sensitization programs are lacking in coordination between DOVVSU and CHRAJ (JSP). In relation to $(\mathrm{M}=3.38, \mathrm{SD}=1.4)$ obtained from the table shows that respondents have the idea that cases should be handled by more than one state institution (DVS). 


\section{(TCDC)}

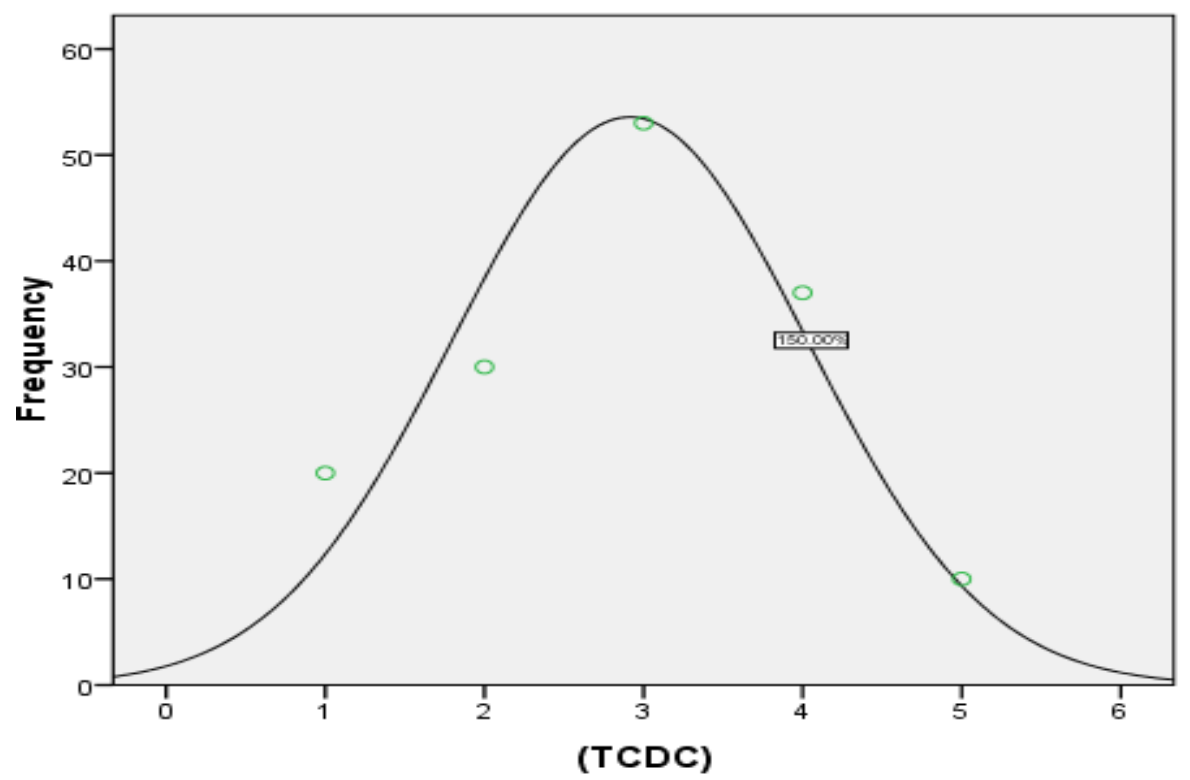

Figure 1:-The graph shows normal skewed feedback from the workers, indicating a neutral idea of existing interorganizational coordination among DOVVSU and CHRAJ. The majority of workers could not ascertain whether or not there's coordination among the organizations in resolving domestic violence cases.

Objective 2

Table 2:-The Importance of formal Information sharing for Inter-organizational coordination.

\begin{tabular}{|l|l|l|l|l|}
\hline \multicolumn{5}{|l|}{} \\
\hline & Mean & Std. Deviation & Skewness \\
\hline & Statistic & Statistic & Statistic & Std. Error \\
\hline (LIS) & 2.66 & 1.399 & .537 & .198 \\
\hline (DIS) & 2.50 & 1.208 & .509 & .198 \\
\hline (MOH) & 2.43 & 1.363 & .722 & .198 \\
\hline
\end{tabular}

Table 2 shows the statistics of information sharing as a mechanism of inter-organizational coordination. Table 2 shows the statistics of information sharing as a mechanism of inter-organizational coordination. From the table, workers indicated that the lack of proper information sharing among the organizations results in unmet needs of domestic violence victims (LIS) with the mean $(\mathrm{M}=2.66, \mathrm{SD}=1.40)$. The table shows $(\mathrm{M}=2.50, \mathrm{SD}=1.21)$ indicating that the disconnection of information sharing ensues improper flow of information when resolving cases (DIS). With reference to the maintenance of organizational hierarchy between state organizations to promote trust in information sharing, the mean obtained was $(\mathrm{M}=2.43, \mathrm{SD}=1.36)$. In order to test the relationship between the variables, we formulated the null and alternative hypothesis as;

1. $\mathrm{H}_{0:}$ : There's no significant relationship between effective performance increment (EPI) and Specialization of a task to reduce conflict of interest in coordination (SRC)

2. $\mathrm{H}_{1}$ : There's a significant relationship between effective performance increment (EPI) and Specialization of a task to reduce conflict of interest in coordination (SRC)

\section{Objective 2}

Table 3:-The need for common organizational culture for inter-organizational coordination.

\begin{tabular}{|l|l|l|l|l|}
\hline & Mean & Std. Deviation & Skewness & \\
\hline & Statistic & Statistic & Statistic & Std. Error \\
\hline (LOCJ) & 2.24 & 1.151 & .936 & .198 \\
\hline (CLVA) & 2.15 & 1.228 & 1.104 & .198 \\
\hline (NOCD) & 2.39 & .933 & 1.569 & .198 \\
\hline
\end{tabular}


Table 3 represents the statistics of how common organizational culture plays a role in inter-organizational coordination. Table 3 seek to depict that lack of common organizational culture leads to conflict in leadership jurisdiction in coordination ( $\mathrm{LOCJ})$, the test showed $(\mathrm{M}=2.24, \mathrm{SD}=1.15)$. The table indicated that the provision of a common language, values and ideology for organizations in coordination promotes trust and efficiency (CLVA) with the mean $(\mathrm{M}=2.15, \mathrm{SD}=1.23)$. Table 4 shows the result of non- functioning Common organizational culture result in disagreement on the decision-making process in coordination (NOCD) with the mean $(\mathrm{M}=2.15$, SD $=1.23$ ). The overall result is an indication that a common organizational culture promotes coordination. Likewise, we formulated a null and alternative hypothesis to examine the relationship between the variable as follows; $\mathrm{H}_{0}$ There's no significant relationship between formal information sharing (FIS) and organizational hierarchy (OM) $\mathrm{H}_{2}$ There's a significant relationship between formal information sharing (FIS) and organizational hierarchy (OM)

\section{Objective 2}

Table 4:-Descriptive Statistics of the importance of the specialization of task for inter-organizational coordination

\begin{tabular}{|l|l|l|l|l|}
\hline & Mean & Std. Deviation & Skewness & \\
\hline & Statistic & Statistic & Statistic & Std. Error \\
\hline (SIP) & 2.07 & 1.147 & 1.151 & .198 \\
\hline (USO) & 2.20 & 1.187 & .873 & .198 \\
\hline (SRC) & 2.03 & 1.114 & 1.292 & .198 \\
\hline
\end{tabular}

The results from table 4 indicate the specialization of tasks as a mechanism for coordination. With the mean $(\mathrm{M}=$ 2.07, SD =1.15) it's an indication that specialization of tasks increases effective performance and reduces administrative cost (SIP). Table 4 showing $(\mathrm{M}=2.20, \mathrm{SD}=1.19)$, its evidence that unclearly specialization of the tasks leads to overlapping of duties or repetition of work in inter-organizational coordination (USO). From table 4, the mean $(\mathrm{M}=2.03, \mathrm{SD}=1.11)$ it's an indication that specialization of task reduces conflict of interest among organizations in coordination (SRC). A null and alternative hypothesis was formulated to examining the existing relationship between the variables, these follow as;

1. $\mathrm{H}_{0}$ There's no significant relationship between organizations conflict of leadership jurisdiction (CLJ) and common organizational culture to promote trust and efficiency $(\mathrm{COC})$

2. $\mathrm{H}_{3}$ There's a significant relationship between organizations conflict of leadership jurisdiction (CLJ) and common organizational culture to promote trust and efficiency $(\mathrm{COC})$

\section{Regressional analysis}

Linear regression was employed to instigate to predict the impact of specialization of the task to reduce conflict of interest has on effective performance increment as showed in table 6. It was noticed or found out that a positive increase in the conflict of interest reduction increases the effective performance thereby proving the variable significant, thus a percentage increase of conflict of interest reduction increases the effective performance of organizations by .69 percent which affirms the alternative hypothesis. A significant regression equation found was $\mathrm{F}$ $(1,148)=153.365, \mathrm{P}<.001$, with $\mathrm{R}^{2}=.509$.

\section{Hypothesis 1}

Table 6:-The impact of specialization of the task to reduce conflict of interest on effective performance

\begin{tabular}{|c|c|c|c|c|c|c|}
\hline \multicolumn{2}{|c|}{ Model } & \multicolumn{2}{|c|}{ Unstandardized Coefficients } & \multirow{2}{*}{$\begin{array}{l}\text { Standardized } \\
\text { Coefficients } \\
\text { Beta } \\
\end{array}$} & \multirow[t]{2}{*}{$\mathrm{t}$} & \multirow[t]{2}{*}{ Sig. } \\
\hline & & $\mathrm{B}$ & Std. Error & & & \\
\hline \multirow[t]{2}{*}{1} & (Constant) & .556 & .139 & & 4.000 & .000 \\
\hline & $(\mathrm{SRC})$ & .690 & .056 & .713 & 12.384 & .000 \\
\hline \multicolumn{4}{|c|}{ a. Dependent Variable: (EPI) } & & & \\
\hline
\end{tabular}

Pearson correlation, significant correlation is marked as; $* * p<.001$

Hypothesis 2

Table 7:-The effect that maintenance of organizational hierarchy has on formal information sharing

\begin{tabular}{|l|l|l|l|l|l|}
\hline \multirow{2}{*}{ Model } & \multicolumn{2}{|l|}{ Unstandardized Coefficients } & $\begin{array}{l}\text { Standardized } \\
\text { Coefficients }\end{array}$ & Sig. \\
\cline { 2 - 4 } & $\mathrm{B}$ & Std. Error & Beta & \\
\hline
\end{tabular}




\begin{tabular}{|l|l|l|l|l|l|l|}
\hline \multirow{2}{*}{1} & (Constant) & .447 & .170 & & 2.626 & .010 \\
\cline { 2 - 7 } & $(\mathrm{OM})$ & .885 & .061 & .764 & 14.419 & .000 \\
\hline
\end{tabular}

Pearson correlation, significant correlation is marked as; $* * p<.001$.

The results from table 7 indicated a significant effect between the maintenance of organizational hierarchy to promote trust and formal information sharing on domestic violence victims' cases. A significant regression equation found was $\mathrm{F}(1,148)=207.899, \mathrm{P}<.010$, with $\mathrm{R} 2=.584$. It was noticed that a percentage increase in maintenance of organizational hierarchy to promote trust increases formal information sharing by 0.89 percent which confirms the alternative hypothesis.

\section{Hypothesis 3}

Table 8:-The effect of organizations conflict in leadership jurisdiction on common organizational culture to promote trust and efficiency

\begin{tabular}{|c|c|c|c|c|c|c|}
\hline \multicolumn{2}{|c|}{ Model } & \multicolumn{2}{|c|}{ Unstandardized Coefficients } & \multirow{2}{*}{$\begin{array}{l}\text { Standardized } \\
\text { Coefficients } \\
\text { Beta }\end{array}$} & \multirow[t]{2}{*}{$\mathrm{t}$} & \multirow[t]{2}{*}{ Sig. } \\
\hline & & B & Std. Error & & & \\
\hline \multirow[t]{2}{*}{1} & (Constant) & 1.097 & .157 & & 7.003 & .000 \\
\hline & $(\mathrm{COC})$ & .533 & .063 & .568 & 8.405 & .000 \\
\hline
\end{tabular}

Pearson correlation, significant correlation is marked as; $* * \mathrm{p}<.001$

In table 8 , the results from the regression data calculated were to predict the relationship between organizations conflict in leadership jurisdiction and organizational culture to promote trust and efficiency, the results showed a positive relationship between the two variables. A significant regression equation was found, $\mathrm{F}(1,148)=70.64, \mathrm{P}<$ .001 , with $\mathrm{R}^{2}=.323$. A percentage increase in organizations' conflict in leadership jurisdiction increases common organizational culture to promote trust and efficiency by .53 percent which endorses the alternative hypothesis.

\section{Discussion:-}

The researcher mainly investigated the impact of inter-organizational coordination on the effective performance of state organizations using data samples from DOVVSU and CHRAJ. This paper identified formal information sharing, specialization of tasks and establishment of common organizational culture as the mechanisms that facilitate and sustain inter-organization coordination. The workers described the existing situation regarding how they manage domestic violence cases. Data disclosed that workers exhibited profound knowledge about the mechanisms of interorganizational coordination, workers revealed that formal communication facilitates interaction and increases the rapid dissemination of information among organizations that can ensure the enhancement of trust which strengthening ties between organizations. Coleman, (1990)

On the regressional analyses, results indicated a positive relationship between formal information sharing and organizational hierarchy. Information sharing improves when organizations operate in a noninterfering environment from state agencies. Thus there would be no loss of information on violence cases and the needs of domestic violence victims will be properly met. A grander number of the workers are of the view that specialization of tasks promotes effective use of resources to increase performance and reduce conflict of interest in coordination. There is an augury to specify the processes by which organizations integrate their activities. Santos, Van der Heyden, Spector et, 2011) Notwithstanding, the positive relationship revealed by the results among the variables; effective performance increment and specification of tasks to reduce conflict of interest, there is the essence for structuring and formalization of coordinated activities to ensure the comprehensive partition of responsibilities to prevent duplication of work. Most workers have the opinion that lack of common organizational culture leads to conflict in leadership jurisdiction and common language, values, and ideology for organizations will ensure efficiency thereby promoting trust among the organizations. This is to confirm that Inter-organizational coordination successes depend on perceptions Su et. al. (2011), structural orders Patriotta, Schultz, Gond et. al, (2011) and organizational factors. H. Jack Walker, Achilles A. and Armenakis, (2007) The results proved that elements of organizational culture common; language, values, ideology and leadership jurisdiction are positively related in achieving the objectives and intentions of inter-organizational coordination. 


\section{Author Contributions:}

All authors equally contributed, read and approved the final manuscript.

\section{Conflicts of Interest:}

The authors declare no contending interest.

\section{References:-}

1. Alexander, E. R. (1993). Article Menu Access Options Article Metrics Cite Share Request Permissions Related Articles Inter-organizational Coordination: Theory and Practice. Journal of Planning Literature, 7(4), 328-343.

2. Barner, J.R. \& Carney, M. M. (2011). Interventions for Intimate Partner Violence: A Historical Review. J Fam. Viol, 26(3), 235.

3. Barnish, M. (2004). Domestic Violence : A Literature Review. HM Inspectorate of Probation, (9), 1-147.

4. Bott, S., Morrison, A. \& Ellsberg, M. (2005). Preventing and Responding To Gender-Based Violence in Middle and Low-Income Countries: A Global Review and Analysis. World Bank Research Working Paper 3618, (June), 61.

5. Coleman, J. (1990). Foundations of Social Theory. Cambridge: Mass: Belknap, Harvard University Press.

6. CRC General Comment No. 13. (2003). The right of the child to freedom from all forms of violence.

7. Cunningham, A., Jaffe, P. G., Baker, L., Dick, T., Malla, S., Mazaheri, N. \& Poisson, S. (1998). TheoryDerived Explanations of Male Violence against Female Partners: Literature Update and Related Implications for Treatment and Evaluation. Focus, (September), 1-81.

8. Dery, I. (2014). Domestic Violence against Women in Ghana: An Exploratory Study in Upper West, 4(12), 1 17.

9. Dutton, M. A., Goodman, L. A. \& Bennett, L. (2001). Court-involved battered women's responses to violence: The role of psychological, physical, and sexual abuse. Psychological Abuse in Violent Domestic Relations, 14(1), 177-195.

10. Edleson, J. L. (1998). Responsible Mothers and Invisible Men: Child Protection in the Case of Adult Domestic Violence. Journal of Interpersonal Violence, 13(2), 294-298.

11. Geerlings, H. \& Stead, D. (2002). Integrating Transport, Land-Use Planning and Environment Policy in European Countries. Ejtir, 2(3/4), 215-232.

12. Geert Bouckaert, B. Guy Peters, K. V. (2010). The Coordination of Public Sector Organizations: Shifting Patterns of Public Management (2010th Edi). Palgrave.

13. Ghana, R. of. (2007). Domestic Violence Act 2007 (Act 732). Interpretation A Journal Of Bible And Theology. Accra.

14. Ghana, R. of. (2018). Medium Term Expenditure Framework. Accra. Ghanaweb.com (2010).

15. H. Jack Walker, Achilles A. Armenakis, J. B. B. (2007). «Factors influencing organizational change efforts ». Journal of Organizational Change Management, 20(6), 761-773.

16. Hague, G., Thiara, R. \& Mullender, A. (2011). Disabled Women and Domestic Violence: Making the Links, a National UK Study. Psychiatry Psychology and Law Psychology and Law, 117-136.

17. Hamberger, L.K. \& Hastings, J. E. (1998). Personality correlates of men who abuse their partners: A crossvalidation study. J.F.Viol, 1(4), 323-341.

18. Heise, L. L. (1998). "Violence against Women, An Integrated, Ecological Framework", Violence Against Women, 4(3), 262-290.

19. Hera, I. V. (s. d.). Good practices for police intervention in gender-based violence Hera project 1. Valencia.

20. Hotaling, G.T. \& Sugarman, D. B. (1990). A risk marker analysis of assaulted wives. J Fam. Viol, 5(1), 1-13.

21. Humphreys, C., Mullender, A., Lowe, P., Hague, G., Abrahams, H. \& Hester, M. (2001). Domestic violence and child abuse: Developing sensitive policies and guidance. Child Abuse Review, 10(3), 183-197.

22. Institute of Development Studies (IDS), G. S. S. (GSS) and A. (2016). Domestic Violence in Ghana: Incidence, Attitudes, Determinants and Consequences. Ids.

23. Jennings Edward T, Ewalt, J. A. G. (1998). Inter-organizational Coordination, Administrative Consolidation, and Policy Performance. Public Administration Review, 58(5), 417.

24. Jewkes, R. K., Dunkle, K., Nduna, M. \& Shai, N. (2010). Intimate partner violence, relationship power inequity, and incidence of HIV infection in young women in South Africa: A cohort study. The Lancet, 376(9734), 41 48.

25. Kissi, P. O. (2012). Addressing Domestic Violence Cases in Ghana: A Study of the Practice Methodologies of 
Accra Regional Dovvsu (University of Ghana). University of Ghana http://ugspace.ug.edu.gh.

26. Krug, E. G., Mercy, J. A., Dahlberg, L. L. \& Zwi, A. B. (2002). Public health. The world report on violence and health. The Lancet Publishing Group, 360, 83-88.

27. Michele C. Black, Kathleen C. Basile, Matthew J. Breiding, Sharon G. Smith Mikel L. Walters, M. T. M. J. C. and M. R. S. (2010). National Intimate Partner and Sexual Violence Survey 2010 Summary Report. Atlanta, Georgia.

28. Patriotta, G., Gond, J. P. \& Schultz, F. (2011). Maintaining legitimacy: Controversies, orders of worth, and public justifications. Journal of Management Studies, 48(8), 1804-1836.

29. Santos, J., Spector, B. \& Van der Heyden, L. (2011). Toward a Theory of Business Model Innovation within Incumbent Firms. SSRN Electronic Journal.

30. Secretariat, T. A. (2015). ASEAN Summit on 18 November 2012; and the commitments of ASEAN as reflected in the ASEAN Leaders' Joint Statement in Enhancing Cooperation against Trafficking in Persons in Southeast Asia adopted at the 18. Jakarta, Indonesia.

31. Su, S. Y. W., Xiao, X., DePree, J., Beck, H. W., Thomas, C., Coggeshall, A. \& Bostock, R. (2011). Interoperation of organizational data, rules, processes and services for achieving inter-organizational coordination and collaboration. Communication présentée au Proceedings of the Annual Hawaii International Conference on System Sciences.

32. Yin, R. K. (1993). Case study methods. Handbook of complementary methods in education research, 111-122. 